\title{
Retos del contador en la actualidad
}

\author{
Mg. CPC Zelma Wong Torres \\ Docente Asociado de la Facultad de Ciencias Contables \\ CPC Luisa E. Salcedo GuZMán \\ Docente Asociado de la Facultad de Ciencias Contables
}

\section{RESUMEN}

Mucho se ha escrito sobre técnicas y prácticas contables, aplicamos las Normas Internacionales de Contabilidad NIC'S y en algunas ocasiones discutimos sobre lo que sustentan una u otra norma; sin embargo, los profesionales contadores públicos no hemos escrito ningún libro al respecto, sólo nos limitamos a repetir lo que leemos o simplemente a aplicar aquellas normas según las circunstancias de la profesión, pero no investigamos el porqué de tales normas; hemos dejado que profesionales de otros paises nos impongan sus intereses, y por consiguiente nuestra profesión sea vista como un último peldaño; sin embargo, poco o nada hemos analizado el porqué de estas apreciaciones y expresiones, a consecuencia de grandes cambios. No será porque no nos damos un tiempo para escribir y analizar o porque no nos sentimos capaces de hacerlo o realizarlo.

La contabilidad a través del tiempo ha evolucionado según las necesidades de los individuos y organizaciones, Si evaluáramos la historia de la profesión contable, desde sus inicios hasta nuestros días, nos percataríamos que la época en la cual se ha convulsionado más el ejercicio de la misma, se sitúa en los años 90.

La Contabilidad, y en su extensión la profesión y su aplicación, marchan en un nuevo orden, cuya naturaleza se encuentra en cambios constantes ocurridos en la última década del siglo XX, como los llamados cambios de paradigmas empresariales, tales como: La globalización, las nuevas tecnologías, la nueva naturaleza de las organizaciones. y un nuevo ambiente de negocios.

El presente artículo pretende que tomemos conciencia de la importancia de asumir los nuevos retos de la investigación contable y de nuestra profesión ante cambios generalizados en el conjunto de las organizaciones, por lo que día a día la investigación se vuelve el único factor de salvación para entrar al nivel que exige la sociedad actual y encontrarnos vigentes ante las innovaciones.

Palabras clave: Nuevo enfoque del contador, retos de la Contabilidad, innovación contable, investigación contable. 


\section{INTRODUCCIÓN}

Es necesario leer a Federico Gertz, en su obra Origen y evolución de la Contabilidad, donde manifiesta que la actividad contable ya existía 6000 años antes de Cristo y que la actividad contable sufre una gran revuelta y reconocimiento gracias a la escritura y los números.

Pagani en su obra El libre comercio (¡Libri Comercial!) manifiesta que había reyes que obligaban a usar determinados libros contables a los comerciantes de esa época.

En la época de Alejandro Magno, cuyo reinado fue uno de los primeros grandes imperios económicos y la influencia de los banqueros griegos era de gran importancia en el imperio, famosos en Atenas, era frecuente examinar las cuentas con mucha habilidad $\mathrm{y}$ destreza cuando se les requería (History of Modern Bank of Issue, Conant).

Se encuentra vestigios en Roma sobre la práctica contable desde los primeros siglos en que fue fundada, los primeros jefes de familia asentaban diariamente sus ingresos y gastos en un libro que conocían como "adversaria" y en otro libro conocido como Codex o Tabulae en los que se anotaban los ingresos (acceptum) y los gastos (expensum).

Durante el periodo comprendido entre 476-1453 después de Cristo, la contabilidad sigue avanzando y encontramos que Francisco Datini (1366-1400) muestra la contabilidad por partida doble; escribe sobre las cuentas patrimoniales por primera vez, o sea, lo que conocemos como el Estado de ganancias y pérdidas, se seguía las huellas de la mercadería en todas sus etapas hasta la utilidad o pérdida del ejercicio, periódicamente.

En el siglo XV, vía la imprenta, se hace conocer la contabilidad mediante el libro de la época Della Mercatura et del Mercanti
Perfetto, cuyo escritor es Benedetto Cotrugli Rangeo, quien terminó de escribir su obra el 25 de agosto de 1458 (publicada en 1573), aquí se identifica claramente la partida doble, menciona tres libros cuaderno (mayor), giornate (Diario) y memoriale (borrador), escribe también que debe elaborarse un Balance y que era necesario llevar el libro copiador de cartas (Libro de actas)

Fray Luca Pacciolo fue quien se refiere por primera vez en 1494 al método contable de la partida doble y en forma de detalle escribe sobre el tema contable que se llevaba en su época.

En el siglo XIX, con el Código de Napoleón, en 1802, comienza a expandirse un movimiento conocido como la revolución industrial, con Adán Smith y David Ricardo, en donde era necesaria la contabilidad, que comienza a sufrir modificaciones de fondo y forma pues surgen los conocidos "Principios de Contabilidad" para lograr su perfeccionamiento. Claro está, con muchas evaluaciones que se efectuarían a través del tiempo, para perfeccionarlas.

Comienzan las organizaciones científicas en buscar el cómo; y se crean los sistemas y métodos, la productividad (¿a qué costo?). Aparece la necesidad de establecer la rentabilidad (¿Es buena la inversión?). Y comienzan a surgir aquí los análisis contables y económicos.

Nace también la eficiencia ( $\_$Es buena la gestión?) y aparece la evaluación vía auditoría, pero también se quería saber ¿a dónde vamos?, por lo que se confeccionan los presupuestos, el cómo hacerlo mejor, nos ubica en las estrategias tan de moda últimamente, es decir, nace la investigación operativa, como los movimientos siguen aumentando, en que la mano del hombre ya no alcanza, se crea la sistematización, o sea, la información integral mediante procesamiento de datos, luego surge la necesidad de establecer 
políticas de gestión, dando las bases para el nacimiento y el desarrollo económico, con gerencias eficiente y efectivas.

\section{CONTABILIDAD DE GESTIÓN}

En conceptos generales, la gestión de empresas o cualquier ente organizado con fines privados o públicos, se ha venido denominando "CALIDAD TOTAL" o "COMPANY WIDE QUALITY CONTROL” (CWQC). El término CALIDAD TOTAL se creó en EE.UU. pero hasta hace pocos años, no tenía un significado preciso. Los japoneses, por el contrario, han hecho de él uno de los pilares de su renacimiento industrial.

Estos nuevos conceptos han originado en este nuevo orden económico el manifiesto de la necesidad de que las unidades empresariales modifiquen tanto sus estructuras de gestión, como los procesos convencionales de toma de decisiones para beneficios de la empresa.

Estamos inmersos en una época de "turbulencia” económica, motivada, en gran medida, por el desarrollo de unos mercados altamente competitivos y desarrollados que han desatado un proceso de innovación y de cambio de consecuencias imprevisibles. Es a consecuencia de ello, que el papel del Contador Público en esta nueva visión de las organizaciones se presta a tener una trascendencia importante para el cumplimiento de los objetivos.

\section{FUNCIONES QUE CUMPLE LA CONTABILIDAD}

Se cimenta sobre hechos reales de las operaciones que realiza la empresa en un tiempo determinado, con sustento en documentos que acrediten la acción realizada; en un tiempo y espacio determinado.
- Función histórica. Día a día se registran operaciones contables en forma cronológica.

- Función matemática y estadística. La información que se proporciona refleja los resultados de la transacción matemática, sea cantidades monetarias, y se informa en muchos casos estadísticamente.

- Función económica. Se deben establecer los costos y beneficios de la empresa a una fecha determinada.

- Función financiera. Se debe analizar la obtención del dinero, de cómo generar recursos, de cómo se deben afrontar las deudas y obligaciones de la empresa.

- Función social. Vía las disposiciones legales, los impuestos, tributos, tasas, contribuciones que debe afrontar la empresa, para destinarlos a un bienestar común.

- Función legal. Conocer los aspectos legales, laborales, tributarios y societarios que afectan a la empresa.

- Función administrativa. Es el orden racional del esfuerzo humano para su éxito personal o empresarial.

\section{SISTEMA NACIONAL DE CONTABILIDAD (SNC)}

Vía ley N.o 28708, del 20/03/2006, publicada el 24/04/2006, solamente mencionaremos los artículos en relación al tema que estamos tratando:

\section{Artículo 13.- Investigación Contable}

La investigación contable es el conjunto de actividades de estudio y análisis de los hechos económicos, financieros, su incidencia en la situación patrimonial, la gestión, los presupuestos y los costos en las entidades de los sectores público y privado, conducentes a la aprobación de normas y al mejoramiento de los sistemas y procedimientos contables. 


\section{Artículo 14.- Normatividad Contable}

La Dirección Nacional de Contabilidad Pública y el Consejo Normativo de Contabilidad, en el ámbito de sus competencias, dictan y aprueban normas y procedimientos contables aplicables en los sectores público y privado, respectivamente.

\section{Artículo 15.- Difusión y Capacitación}

La Dirección Nacional de Contabilidad Pública, desarrolla las acciones necesarias para la difusión, capacitación y permanente actualización de las normas y procedimientos contables vigentes.

Aquí nos preguntaríamos: ¿Se cumple a cabalidad, la coordinación con las Universidades o las empresas para hacer difusión uniforme?

\section{APTITUD Y ENTORNO DEL CONTADOR PÚBLICO}

Conscientes de que al escribir la historia de la contabilidad faltan algunos aspectos por ello recomendamos leer el artículo "Historia de la contabilidad", escrito por las mismas autoras en la Revista Quipucamayoc 2008-I. La necesidad de la Contabilidad nace con la humanidad y se desarrolla con los cambios.

Hoy en día las organizaciones se encuentran en constantedesarrollo para estar en condiciones de participar con éxito en un ambiente cada vez máscompetitivoa nivel nacional einternacional. La experiencia del Contador Público le permite realizar actividades profesionales en diferentes áreas dentro de la organización, como lo son: Contabilidad de Costos, Contabilidad Administrativa, Contraloría, Tesorería y en áreas externas como: Auditoría, Consultoría y Asesoría, en todo lo relativo al vasto ámbito del desempeño del Contador.
Sin duda, es el entrenamiento y la preparación que recibe el Contador Público durante su formación profesional, los que le permiten tener una ventaja competitiva sobre algunas otras disciplinas. Por su preparación y desarrollo profesional, el Contador Público participa muy activamente sobre los elementos vitales en la operación de las empresas, gestión económica y empresarial.

Los constantes y rápidos cambios en el entorno, como consecuencia de la internacionalización de las empresas, la complejidad en el manejo y control de las operaciones por ellas realizadas, la globalización de la economía, la apertura comercial, el desarrollo de nuevos procesos y productos, la formación de grupos internacionales, el desarrollo tecnológico, han propiciado que el Contador Público participe indiscutiblemente en las empresas más activamente $\mathrm{Y}$ que deba tener una actitud proyectista de la empresa y de los objetivos que espera en beneficio de la organización.

\section{LA EDUCACIÓN Y LA INSTRUCCIÓN DEL CONTADOR PÚBLICO}

Aunque algunos piensen que es lo mismo educar e instruir, esto no es cierto.

La educación es el fin del hombre mismo, no basta ser instruido; hay que ser mejor persona, ser ético.

El que acumula mucho saber utilitario y no le importan los demás es un ser bárbaro y que todo lo valora en término de provecho $y$ dominio, lo convierte en un vegetal inteligente que actúa como animal de presa.

Las universidades pierden su identidad al descuidar su posición formativa y al atender sólo la eficiencia pragmática, funcional o admisnitrativas, solamente con fines utilitarios, un sistema educativo sin respuesta es un sistema sin ética. 
Joaquín Gómez Mofirm, en un artículo reciente, menciona: "La educación no debe ser una nueva trasmisión de conocimientos. Lo verdaderamente esencial es que se estimule tanto en los alumnos como en los profesores la sed de saber, al mismo tiempo se requiere la formación humanística de tal modo que el estudiante, al convertirse en profesional, llegue a ser un hombre creativo e integrado afectivamente a la sociedad".

El contador debe tener moral, el alumno deberá obtener conocimiento y normas éticas de conducta. El filosofo Maritaín decía que "la tarea de la educación moral se está convirtiendo con filosofías materialistas y positivistas que relativizan completamente los patrones morales".

\section{LA ÉTICA}

Ética viene del griego ethos, que significa mora$\mathrm{da}$, es decir, comportamiento moral.

Es necesario la enseñanza de ética profesional, teniendo presente lo dicho por Humboldt "Si queremos lograr profesionalitas con ética, hay que enseñarles a serlo y cómo serlo".

La ética es un conjunto de principios que sirven de guía para que el ser humano sea feliz el conocimiento al qué, por qué y para qué, es un supuesto previo necesario. Debemos esforzarnos para leer más, para reflexionar acerca de la ética. Debemos pensar, decidir escribir hacer y actuar, con principios éticos basados en la verdad y no por apariencias.

Los problemas engendran creatividad, sin riesgo no hay fracasos; pero sin riesgo, tampoco habría éxito, por lo que deberá conocer los principios éticos para aplicar acciones, se debe contar con valores morales para que se acredite ante la sociedad la luz de la ética, es el éxito a mediano y largo plazo fuente de orgullo creatividad y compromiso personal.
Los principios éticos que debe cumplir el contador son: integridad, objetividad, independencia, responsabilidad, confidencialidad, observancia, competencia, difusión, respeto y buena conducta.

Ética es la parte fundamental de la filosofía práctica que se ocupa de las normas de la conducta humana, según Aristóteles; el área de desarrollo de la persona.

\section{CONCLUSIONES}

El Contador Público, al igual que las empresas, tiene que preparase y desarrollarse en los nuevos ambientes cada vez más competitivos.

Los conocimientos académicos y los obtenidos a través de los años, le permiten al Contador Público agregar valor ético a la información financiera, la guía de normas y principios de actuación, la observancia de un código de ética profesional y el cumplimiento de la educación continua, le dan en la sociedad un lugar destacado.

La globalización de la economía, la apertura comercial, el desarrollo de nuevos procesos y productos, la formación de grupos internacionales, el desarrollo tecnológico, a propiciado que el Contador Público participe en las empresas más activamente en beneficio de la misma, de la sociedad y del país.

\section{REFERENCIAS}

Romero López, Álvaro Javier. Principios de Contabilidad. McGraw Hill.

Buzadzic, M.; Habek, M.; Styptics, V.; Niven, D.: "Los programas de gestión de calidad en tiempos difíciles", Harvard-Deusto Business Review, mayojunio, 1993. 
Galgano, Alberto. Calidad Total: Clave estratégica para la competitividad de la empresa. Central Artes Gráficas, 1993.
Vandeville, Pierre. Gestion et controle de la qualite. AENOR, 1990. 